\title{
Evaluation of the Impact of Moroccan Cultural Diplomacy: Tools, Challenges and Insights -The Ministry of Foreign Affairs, African Cooperation and Moroccan Expatriates as a Case-Study
}

\author{
Fatima Zahraa Boutabssil (iD \\ Ph.D. Student, Department of English Language and Literature Faculty of Languages, Letters and Arts, Ibn Tofail University- \\ Kenitra, Morocco \\ $\triangle$ Corresponding Author: Fatima Zahraa Boutabssil, E-mail: Boutabssil@hotmail.fr
}

ARTICLE INFORMATION ABSTRACT

Received: January 18, 2021

Accepted: February 14, 2021

Volume: 4

Issue: 2

DOI: 10.32996/ijllt.2021.4.2.24

\section{KEYWORDS}

Cultural diplomacy, Moroccan

Ministry of Foreign Affairs,

evaluation tools, impact,

challenges, strategy, the

Directorate of Cooperation and

Cultural Action
This paper sheds light on the tools used by the Moroccan Ministry of Foreign Affairs to evaluate the impact of cultural diplomacy. It relies on extensive qualitative fieldwork carried out at the Directorate of Cooperation and Cultural Action. The study aims at depicting the challenges that Moroccan cultural diplomacy faces and the extent to which these challenges influence evaluation practices. It adopts a case-study design based on the use of semi-structured interviews, observation and document analysis. The findings reveal that the evaluation is based on reports elaborated by posts abroad, and on the study of Morocco's reputation conducted by the Royal Institute of Strategic Studies. The findings also show that the challenges that influence the establishment of effective evaluation strategies reside in the lack of human and financial resources, the depreciation of the potential of cultural diplomacy, the multiplicity of actors, issues of attribution and the lack of understanding of soft power practices. This paper also argues that the strategy deployed by the Moroccan Ministry of Foreign Affairs represents the main challenge that hinders the evaluation of Moroccan cultural diplomacy, and suggests the establishment of a unified cultural diplomacy strategy between Moroccan cultural diplomacy actors based on the logic model.

\section{Introduction}

Cultural diplomacy is the exchange of ideas, information, values, systems, traditions, beliefs, and other aspects of culture with the intention of fostering mutual understanding (Cummings, 2009, p, 1). Practiced by state actors, non-state actors or even through private initiatives, culture remains a determining factor in the conduct of international diplomacy.

After his succession to the throne, His Majesty King Mohammed the Sixth stressed the importance of cultural diplomacy in Morocco's foreign policy and the necessity of establishing cohesive and coherent cultural actions abroad. Aware of its importance, His Majesty urged, through his speech in the Conference of Ambassadors in 2013, that it is important to give Moroccan cultural diplomacy the support and encouragement it deserves through the establishment of 'Les Maisons du Maroc' and Moroccan Cultural Centers (MCCs) abroad, the intensification of artistic activities, the organization of fairs and exhibitions, and the promotion of the civilizational and cultural heritage of Morocco to increase its influence abroad and to highlight its unified, authentic, rich and plural identity ("Le Message du Souverain à la 1ère Conférence des Ambassadeurs", 2013).

Domestically, cultural diplomacy is used as a lever of influence for a stable Morocco, united and open to the other. Internationally, it is based on the establishment of a more professional and less traditional diplomatic vision by promoting the Moroccan culture abroad as a lever for change, national projection, and cultural influence.

In Morocco, previous research in the cultural diplomacy field has focused solely on discussing the assets of Moroccan cultural diplomacy. No attempts have discussed how the Moroccan Ministry of Foreign Affairs evaluates the effectiveness of its cultural diplomatic actions abroad. This paper attempts to fill in this gap. First, it explores the evaluation tools used by the Moroccan

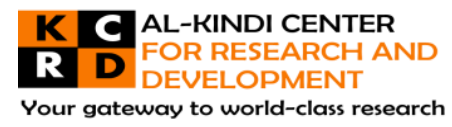

K C AL-KINDI CENTER $\mathbf{R}$ D DEVELOPMENT Your gateway to world-class research

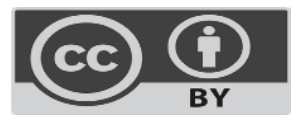

Published by Al-Kindi Center for Research and Development. Copyright (c) the author(s). This open access article is distributed under a Creative Commons Attribution (CC-BY) 4.0 license 
Ministry of Foreign Affairs in assessing the impact of cultural diplomacy programs abroad. Second, it investigates the challenges, if present, that may hinder the establishment of a well-developed impact evaluation strategy. Third, it provides insights on how the Moroccan Ministry of Foreign Affairs can improve the way through which it evaluates its cultural diplomatic programs. Therefore, the central question that this paper tries to answer is as follows:

- How does the Moroccan Ministry of Foreign Affairs evaluate the impact of cultural diplomacy?

This paper also answers the following two sub-questions:

- What are the challenges that prevent the establishment of effective performance indicators in the Moroccan context?

- To what extent do the current measurement tools used by the Moroccan Ministry of Foreign Affairs give account to CD practitioners of the effectiveness of their programs and policies?

\section{Literature Review}

Evaluation can be defined as a systematic assessment of the worth or merit of an object (The Joint Committee 1994, as cited in Stufflebeam \& Shinkfield, 2007). Evaluating the impact of cultural diplomacy is crucial in the cultural diplomacy cycle. After formulating, planning and implementing programs, policy-makers need to consider monitoring and evaluating the impact of these programs. This allows cultural diplomacy practitioners to collect information about the degree of success of a specific program or event. In this context, Vinter and Knox (2008) state that:

Measurement provides a means of accountability and enables policy-makers to deploy resources more effectively. At the operational level, it would give managers targeted feedback to enable them to improve performance and focus efforts on those kinds of interventions that have been shown to be most effective $(p, 161)$.

Chitty et. al (2016, as cited in Singh, MacDonald \& Son, 2018) identified two focus points for soft power evaluation. According to them, evaluation needs to consider how soft power activities establish credibility and generate trust in audiences. Evaluation should also consider the way through which soft power actors are perceived. Singh, MacDonald, and Son (2018) add that evaluation should be able to examine how the preferences and the choices made by the target groups have been affected. However, in addition to establishing trust, credibility, and contributing to behavioral shifts, cultural diplomacy also aims at advancing political and economic interests. It would be accurate to say that evaluation should also cover the extent to which cultural diplomacy has contributed to achieving policy goals.

Evaluation is performed in many ways. The Foreign and Commonwealth Office, in the case of the UK, for instance, has been evaluating its public diplomacy actions using reports based on opinion polling and media metrics (Vinter \& Knox, 2008). According to the same study, the British council has been using a more developed system based on assessing performance across a range of factors including project impact, customers and stakeholders' satisfaction, reputation, financial and management results as well as the perceptions of staff (APA, 2008). According to the literature, these methods have failed to demonstrate how the outcomes desired are achieved and are limited to output evaluation (Singh, MacDonald \& Son, 2016).

In another context, according to a study carried out by Sommerfeldt and Buhmann (2019) on the evaluation of the impact of American public diplomacy, it was found that there is a great dependence on the use of reports that rely on tracking participation rates and on media metrics. The findings reveal that such indicators give account on outputs rather than impact and are the most frequently used because they are the easiest to acquire and report (APA, 2019).

In the same context, Gonzalez (2015) describes the evaluation of the impact of American PD as a "reporting culture" of outputs. She stressed the importance of developing an "evaluation culture" that supports objective, rigorous and honest analysis of impact measurement $(p, 36)$. Sommerfledt, Buhmann and Gonzalez maintain that the evaluation based on reports is limited to reporting short-term results. Communicating participation rates does not demonstrate how a certain policy goal has or hasn't been achieved nor does it show how the perceptions of foreign audiences have been altered and improved.

This brings us to the difficulty of impact evaluation which can be demonstrated in the difficulty of measuring certain cultural diplomacy goals. Cull (2007) advances that attempts to evaluate cultural diplomacy can seem like a forester running out every morning to see how far his trees have grown overnight $(p, 43)$. Vinter and Knox (2008) state that the long-term ambition of such practices represents the main obstacle against impact evaluation. Similarly, Gonzalez (2015) advances that concrete change needs 
time and that behavioral shifts and call to action need decades to be achieved and usually require more than just PD tools and resources.

Indeed, the intangible goals of cultural diplomacy are hard to measure. Governments use cultural diplomacy as a tool of raising trust and improving relationships. In the absence of adequate evaluation tools, assessing how far a country has been able to raise trust and improve its relationships with foreign audiences is no easy task to do. Vinter and Knox (2008) expand Cull's metaphor and advance that measuring such intangible goals seems like a forester going out to measure how far his trees have grown overnight without a ruler $(p, 164)$. Cull's metaphor implicates that the nature of cultural diplomacy requires continuous investment and a long-term commitment before it generates results. It also implies that evaluation of impact cannot be done and performed regularly or "overnight" especially when willing to evaluate how far foreign audiences have changed their perceptions about a country.

This discussion also leads us to consider if policy-makers can tell whether the perceptions of foreign audiences change because of the effect of cultural diplomacy and not because of any other diplomatic actions. Vinter and Knox (2008) underline that this can be another challenge hindering the evaluation of soft power practices. Governments that claim to carry out investigations on their countries' reputation cannot tell whether the audiences evaluated appreciate a country because of its government cultural diplomatic actions, a documentary they watched, a dish they had the opportunity to try or a friend who talked to them about the country. Making such correlations needs a high level of precision and the use of more than just output indicators.

Attribution in this context concerns also the different cultural diplomatic actions practiced by different entities engaged in the practice of cultural diplomacy (Vinter \& Knox, 2008). In a world where multiple organizations and influences are acting upon the same complex policy issues, it becomes difficult if not impossible to state if the evaluation performed relates to cultural diplomacy actions carried out by a certain entity (APA, 2008). In other words, contemporary diplomatic practices are not peculiar to state actors. Non-state actors including NGOs, think tanks and associations are now engaged in cultural diplomatic missions. Moreover, some of their actions can even take place independently from governments. This dispersion of actions implies that the impact state actors are evaluating can actually be the impact of actions carried out outside their supervision.

In addition to attribution, Sommerfeldt and Buhmann (2019) discuss that the plurality of soft power actors can be another factor that hinders the evaluation of impacts. It was found, through their study, that the plurality of actors involved in the practice of PD, thus the multiplicity of their interests, goals and actions, leads to problems of inconsistency both at the level of the evaluation approaches used and at the level of clarity of some public diplomacy goals. This confusion ends in a lack of visibility on "who does what?" and "who evaluates what?" It is further accentuated when different actors generate different results; "what if Bureau A generates positive results while Bureau B generates negative ones?" "What results should we take into account in programplanning and strategizing?" "What conclusions can be drawn on the basis of different results?" It is therefore very important for governments to be aware of these elements before deciding on their strategies as well as on the evaluation approaches. Gonzalez (2015) states that this dispersion of evaluation approaches across various bureaus and offices can be one of the most serious challenges facing evaluation today.

Another important factor that prevents the development of effective evaluation strategies is the absence of professionals trained in the field. Assessing the impact and effectiveness of cultural diplomacy necessitates forming profiles able to carry out such practices. This was approved by Sommerfledt and Buhmann (2019) who found that, within the U.S. State Department, there is a lack of profiles qualified to carry out impact evaluation. In the same context, Brown (2017) advances that evaluation is a specialty that requires real qualitative and quantitative research skills not common among official and unofficial practitioners of public diplomacy and the same can be said about cultural diplomacy. This implies that cultural diplomacy officials cannot carry out impact evaluation. Thus, training profiles equipped with the necessary tools to perform such practices is important.

This section has reviewed some of the tools used in the evaluation of the impact of soft power practices used by public diplomacy and cultural diplomacy stakeholders. This discussion does not exclude or undervalue the use of reports in assessing the effects of cultural diplomacy; however, it suggests that the indicators used in these reports fail to give account of certain intangible goals cultural diplomacy aims to pursue. Moreover, this section addresses the challenges that prevent the development of effective evaluation strategies. Since no study on the evaluation tools used by the Moroccan Ministry of Foreign Affairs has been carried out, this paper tries to explore the above-mentioned concepts and their relevance to the Moroccan context.

\section{Methodology}

The realization of this paper relied on an extensive qualitative investigation carried out at the Moroccan Ministry of Foreign Affairs. Specifically, the fieldwork was carried out at the Cultural Department within the Ministry referred to as "The Directorate of Cooperation and Cultural Action" and at the Moroccan Academy of Diplomatic Studies. Qualitative methodology was revealed to 
be the most appropriate in conducting this study as it allowed having direct contact with officials within the Ministry of Foreign Affairs.

\subsection{Sampling and participants}

Purposive sampling was used for the completion of the present paper. More specifically, expert sampling was employed because only experts in the field of cultural diplomacy can provide actual and accurate information regarding the issues under study. The participants who took part in the fieldwork are:

- The Head of the Directorate of Cooperation and Cultural Action.

- The Head of the Division of Scientific, Educational and Cultural Cooperation.

- The Head of the Division of Cultural Action.

- The Head of the Moroccan Academy of Diplomatic Studies.

- Other low-rank officials within the Directorate of Cooperation and Cultural Action.

\subsection{Data collection methods}

Since this study uses qualitative methodology, the fieldwork relied on three qualitative methods: participant observation, document analysis and semi-structured interviews.

\subsection{Observation}

Observation was used as a primary method of data collection in this study. During the three months of fieldwork, a participant, structured and uncontrolled observation protocol was carried out. This protocol consisted of observing and taking part in multiple tasks within the cultural department. The observation also included attending multiple meetings held by the heads of divisions within the cultural department: the Division of Cultural Action and the Division of Scientific, Educational and Cultural Cooperation.

\subsubsection{Document analysis}

The documents were collected during the field research at the Ministry of Foreign Affairs during a period of time of three months (December 2019-February 2020). These documents concerned the files that organize communication between the Ministry's Cultural Department and other state and non-state cultural diplomacy actors. The fieldwork aimed at examining the cultural diplomacy projects implemented, evaluation reports elaborated by posts abroad, the Ministry of Foreign Affairs performance reports (Law of Finance Projects: 2020, 2021), action plans, reports of cultural cooperation held with countries abroad, and reports on the study of Morocco's reputation in the world.

\subsubsection{Semi-structured interviews}

The use of semi-structured interviews has allowed determining the influences of subjective aspects in the policy-making process. They also assisted in understanding the motivations, preferences, desires, and perceptions of those involved in decision-making. The question guide was developed based on the information gathered from the observation protocol and document analysis along with the aspects discussed in the literature review.

\subsection{Data analysis procedures:}

As recording interviews was prohibited within the Ministry, data was collected through note-taking. Member-checking was used to ensure the validity of the data gathered. To analyze the data, the following procedures suggested by Creswell (2014) were used:

Figure 1: Qualitative data analysis procedures: 


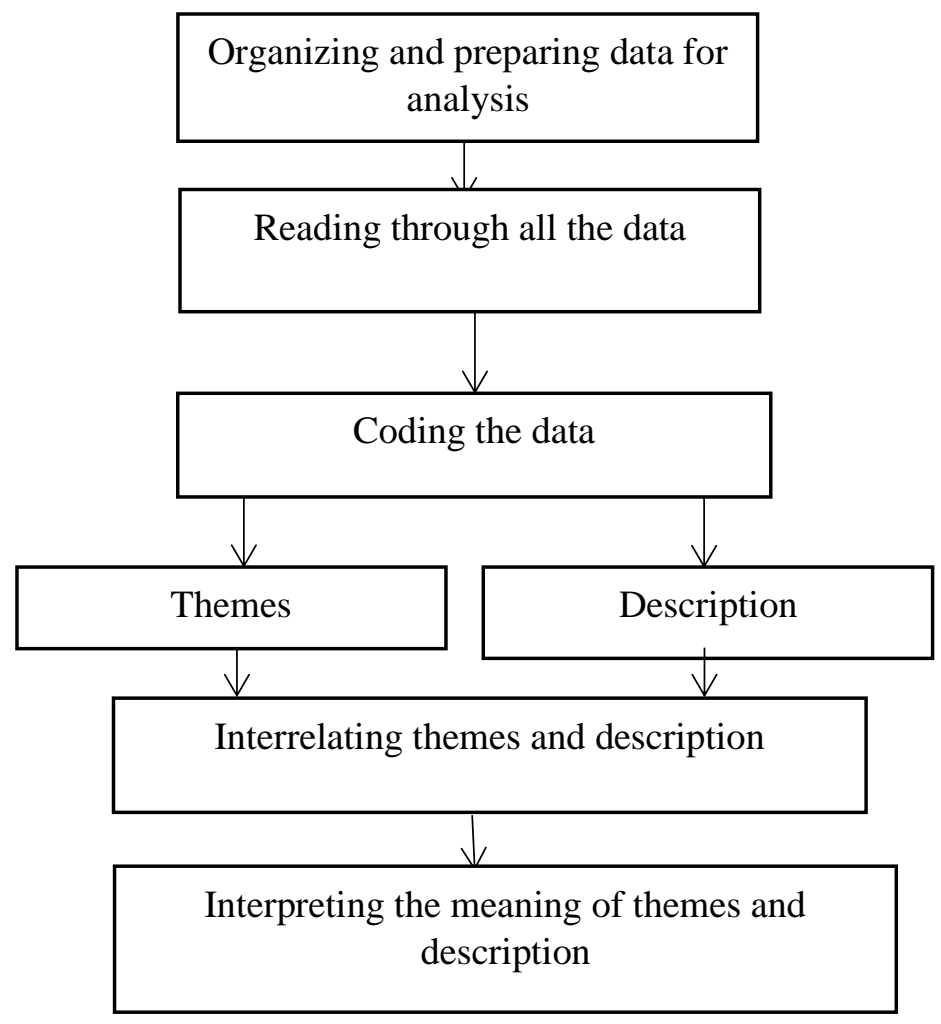

Hand-coding was used in the coding process. The analysis and interpretation of the obtained data is done on the basis of what was discussed in the literature review and on the researcher's personal experiences.

\section{4. findings}

The fieldwork at the Ministry of Foreign Affairs aimed at carrying out an exploratory study on the impact evaluation tools used by the Directorate of Cooperation and Cultural Action which is the main department within the Ministry in charge of carrying out cultural action abroad. As the fieldwork was taking place, many themes appeared. The table below displays the themes found through the study:

Table 1: The themes found in the study

\begin{tabular}{|l|l|}
\hline Theme 1: & Qualitative tools \\
\hline Theme 2: & Quantitative tools \\
\hline Theme 3: & Adaptive strategy \\
\hline Theme 4: & Training of diplomats \\
\hline Theme 5: & Overlooking the role of cultural diplomacy \\
\hline
\end{tabular}

\subsection{Qualitative tools}

The outcome of the fieldwork reveals that the evaluation of Moroccan Cultural Diplomacy is performed using qualitative and quantitative tools. Qualitatively, evaluation is performed through the use of reports that posts abroad elaborate after flagship events. These reports contain detailed information on the objectives and the schedule of the event organized, the human and financial resources deployed, the participants, the activities implemented (lectures, exhibitions, workshops...), and the aspect of Moroccan culture that these activities showcase. The reports also provide information on the attitudes of the audience towards the event; namely, how satisfied they were vis-à-vis the activities they attended. The collection of data concerning the attitudes of participants is generally based on opinion-polling. This information can also be deduced from the personal perceptions of Moroccan diplomatic corps organizing the event.

Other indicators used in the reports concern how the local media reacts towards the event. The fieldwork reveals that media coverage represents an important element in the evaluation of Moroccan cultural diplomatic programs. It is considered by Moroccan cultural diplomacy practitioners to be proof of success and positive influence. 
However, the reports elaborated by posts abroad do not provide any specific data on how the behaviours of participants have been influenced on a long-term basis or how a specific policy goal has been achieved. Only hints could be mentioned on how the event can potentially contribute to achieving that policy impact. The reports also provide recommendations to the Ministry of Foreign Affairs on how to improve the Cultural Department's strategy in terms of the quality of cultural diplomatic programs to take place in the future.

The document analysis also reveals that other indicators are used in the evaluation of Moroccan cultural diplomacy. These indicators are represented as follows:

- Support of non-state actors in paradiplomacy: the number of non-state actors receiving financial support from the Ministry, the number of non-state actors receiving technical support from the Ministry.

- The number of foreign diplomats who benefit from training in the Moroccan Academy of Diplomatic Studies

- The number of agreements, treaties, memoranda of understanding, conventions concluded with other countries on different levels (political, economic, cultural...)

- The number of activities carried out to support Morocco in international and regional organizations: the number of international meetings in which Morocco participates, the number of conferences organized by the Ministry

- The number of high-level political contacts to promote relations with other countries (meetings, visits...).

- The number of countries with which Morocco maintains relationships of friendship and cooperation.

It is worth noting that cultural diplomacy practitioners are aware that these indicators serve exclusively to give account of outputs and are in no way useful for impact evaluation. These indicators are used in reports developed by officials within the Ministry to assess the effectiveness of Morocco's cultural diplomacy strategy.

\subsection{Quantitative tools}

Quantitatively, the evaluation of the impact of Moroccan cultural diplomacy is carried out at the level of the Royal Institute of Strategic Studies through a study of Morocco's reputation conducted on a yearly basis. The study aims to examine the strengths and weaknesses of Morocco in terms of its internal and external reputation. However, Moroccan cultural diplomacy practitioners consider it an indicator of how Morocco is perceived abroad and base their strategies and policies upon its results. According to the study, reputation is evaluated based on the following indicators (The Royal Institute of Strategic Studies, The RepTrak Company, 2020):

- Lifestyle

- Natural appeal

- History and culture

- Economic environment

- Political institutions

- Admired leaders

- Companies and brands

- Natural resources

- Quality of products

- Tourism and leisure

Initially, the study aims to explore the correlation between supportive behaviours and Morocco's reputation. Supportive behaviours are used as indicators in the study. They inform on whether the participants in the survey are willing to either live, invest, study, work, buy products or attend cultural events in the country. In addition, the study aims to investigate the extent to which these indices impact the following (The Royal Institute of Strategic Studies, The RepTrak Company, 2020):

- Exports

- Foreign direct investment

- Tourists arrival

- Immigrants arrival

- International students' arrival

- Improving public diplomacy

This study is also based on the Pulse model that measures the admiration, respect, good impression and trust that one country has towards another one based on three factors including seventeen indicators as shown in the table below:

Figure 2: The indicators used in the study of Morocco's reputation 


\begin{tabular}{|c|c|c|}
\hline Life quality & Institutional quality & Development \\
\hline $\begin{array}{ll}\text { - } & \text { Friendly population } \\
\text { - } & \text { Natural landscapes } \\
\text { - } & \text { Lifestyle } \\
\text { - } & \text { Touristic destination: leisure } \\
& \text { and entertainment }\end{array}$ & $\begin{array}{ll}\text { - } & \text { Security } \\
\text { - } & \text { International respect } \\
\text { - } & \text { Social well-being } \\
\text { - } & \text { Political and institutional } \\
& \text { environment } \\
\text { - } & \text { Economic environment } \\
\text { - } & \text { Efficient use of resources } \\
\text { - } & \text { Ethics and transparency }\end{array}$ & $\begin{array}{l}\text { - } \text { Trustworthy and educated population } \\
\text { - Rich culture } \\
\text { - } \text { Quality of products and services } \\
\text { - Educational system } \\
\text { - Innovation and technology } \\
\text { - Recognized brands and companies }\end{array}$ \\
\hline
\end{tabular}

(The Royal Institute of Strategic Studies, The RepTrak Company, 2020)

As shown in the figure above, the indicators used in the pulse model evaluate perceptions on three levels: the cultural, the political and the economic. In addition to the above-mentioned indicators, a new dimension was added to the study in 2017. This modification lies in the introduction of the filter of familiarity that eliminates respondents who are not familiar with the country. However, the data consulted reveals the absence of relatedness between the results of the study and Moroccan cultural diplomacy.

\subsection{Adaptive strategy}

The strategy adopted by the Moroccan Ministry of Foreign Affairs in the conduct of cultural diplomacy was disclosed to be an important factor that influences the effectiveness of Moroccan cultural diplomacy and makes the generation and evaluation of impact more difficult. This strategy can be characterized by its adaptive nature. It was qualified, in the words of the Head of the Directorate of Cooperation and Cultural Action, to be adaptive to "the timing and context". The Head explained that "strategizing in the adaptive context means that we are continually watching the international scene, detecting any problems that are likely to happen and responding through a portfolio of initiatives". For Morocco, this strategy allows achieving instantaneous effects, thus, gaining the output in a shorter period of time. The adaptive strategy is applied to the Moroccan context specifically when it is related to the Moroccan Sahara issue; i.e, mobilizing actions whenever "things go wrong". The adaptive strategy states that "we will do whatever can be done to solve the problem"; however, it also means that once the problem is solved, we will step back and focus on something else". This lack of continuity and interruption of actions, on a long-term basis, makes it difficult for the country to generate long-term outcomes. Strategizing to solve political crises instead of continually investing in the cultural sector cannot produce long-term impact. This is not to say that the adaptive is ineffective, however, on a long-term basis, it cannot attain what cultural diplomacy aims to achieve.

\subsection{Overlooking the role of cultural diplomacy}

The semi-structured interviews and the document analysis carried out at the level of the Directorate of Cooperation and Cultural Action revealed important information. In terms of the budget allocated to cultural diplomacy, only $1 \%$ of the Ministry's overall budget is devoted to cultural diplomacy, public diplomacy and communicative diplomacy. This budget is managed by practitioners at the level of the General Directorate where and when need be. The document analysis also revealed that the Ministry of Culture is regularly urged to provide financial and logistic resources in order to carry out cultural events abroad. Most of the time, the Ministry of Culture rejects financing the events because of a lack of resources. Some cultural events can even be canceled if no financial resources are available. Some other times, as in the case of Morocco's participation in the Francophonie in 2019/2020, it was revealed from the documents examined that the participation of artists, chefs, musical troupes, and intellectuals in the Francophonie events has been canceled because of financial limitations. Instead, "Morocco's participation in the events was limited to the diffusion of Moroccan films provided by the Moroccan Cinematographic Center because it demanded no financial efforts", an official within the Cultural Department explains. Therefore, the importance allocated to cultural diplomacy could be translated in terms of the budget devoted to the practice. We could venture and say that cultural diplomacy is undervalued by Moroccan decision and policy-makers and more emphasis is rather put on other diplomatic work namely economic diplomacy as it is believed to generate impact on a shorter period of time as opposed to the long-term nature of cultural diplomacy. This could further be explained in two ways. In one of the interviews carried out at the Cultural Department, an official explained that:

"Moroccan Cultural Diplomacy has been lately focusing on attracting Latin American countries to support the Autonomy Plan presented by Morocco regarding the Moroccan Sahara issue. For some time, cultural diplomacy seemed to work well especially with the establishment of the Moroccan Cultural Center in Chile (the Mohammed VI Cultural Center of dialogue of Civilizations), and some Latin American countries eventually expressed their support to Morocco's cause. However, at a certain point in time, cooperation needed to take other directions. These countries approached the Moroccan government to solicit their investors to invest in Latin America". 
The official went further to explain that cultural diplomacy ceased to "do the job" and that culture alone, despite its potential, needs to be combined with other actions for more fruitful results. These reasons may be a factor behind the underestimation of the role of cultural diplomacy in the Moroccan context and thus making economic diplomacy a priority in Morocco's foreign policy. This could be further explained through the pillars of the Moroccan Diplomacy that are based on giving priority to economic diplomacy and encouraging cultural diplomacy. It follows that economic and cultural diplomacy are not given the same importance and value in the country's foreign policy.

\subsection{Human resources:}

While investigating on "who does impact evaluation" or "who is supposed to do impact evaluation", an intrinsically germane theme appeared represented in the lack of officials specialized in the field of cultural diplomacy and the absence of profiles trained in the impact evaluation area. For more information, an interview was performed with the Head of the Moroccan Academy of Diplomatic Studies (AMED). It is a specialized academy within the Moroccan Ministry of Foreign Affairs designated to provide professional training and education to Morocco's diplomatic corps as well as foreign diplomats. The Moroccan diplomats receive a pre-service training of six months within the Academy and another six months of internship at one of the Directorates in the Ministry. It was revealed that these young recruits benefit from multidisciplinary training with no specific emphasis on the cultural diplomacy area. This means that the freshly-recruited diplomats do not receive training programs in the field of CD per see. Instead, "they attend conferences, seminars and cultural days on the subject", explains the Head of the Academy.

In addition, the majority of officials working at the Directorate of Cooperation and Cultural Action, for instance, have not been trained to carry out cultural action. Furthermore, there is a lack of consideration of "who should be where"; i.e, a lack of consistency between the academic field of specialization of these young recruits, the tasks they are assigned to do and the positions they are given within the Ministry. An official within the Directorate of Cooperation and Cultural Action mentioned that "I am here in the Directorate of Cooperation and Cultural Action because I was affiliated here... and I do not think i am qualified enough for this". Some other officials expressed that they have been affiliated to the Directorate of Cooperation and Cultural Action temporarily because of a "lack of personnel" within the department although they were not initially trained to carry out cultural action.

Therefore, to claim that, in the context of Morocco, there are cultural diplomacy officials who truly understand how cultural diplomacy should be carried out is a big claim. Along with that comes the issue of training profiles in the impact evaluation area. It has been noticed within the Moroccan Academy of Diplomatic Studies, young diplomats do not benefit from training to develop such practices. This, to our knowledge, stems from a devaluation of the importance of impact evaluation not only in cultural diplomacy but in all other similar diplomatic actions. This was further elaborated through the interviews carried out with officials within the Directorate of Cooperation and Cultural Action who confirmed they have received no training concerning neither the importance of impact evaluation nor how to conduct it.

\section{Discussion}

\subsection{The multiplicity of cultural diplomacy actors: What/Whose actions are we evaluating?}

Moroccan cultural diplomacy is practiced by a variety of actors. More than twenty entities are in charge of carrying out cultural action abroad, each in its own field of specialization. Through the fieldwork carried out, it was found that each entity evaluates the impact of its own action independently from other cultural diplomacy stakeholders using various indicators that were revealed to be performance and output indicators instead of impact indicators. The fieldwork also revealed the absence of an interinstitutional coordination. This results in a dispersion of actions and interests. This was also approved through the interviews carried out with the head of the Division of Cultural action who stated that "(they) have to start thinking about creating a 'unifying entity' specialized in carrying out Moroccan cultural diplomacy actions instead of having each actor operating independently". The plurality of actors, according to him, "prevents the elaboration of a clear and unified cultural diplomacy strategy, which in turn influences negatively the effectiveness of Moroccan cultural diplomacy".

In addition to this, the study of Morocco's reputation abroad has limitations. The shortcomings of this study are represented in the lack of clarification of whose actions are being evaluated. Through the documents consulted, the study itself claims that the data gathered on Morocco's reputation abroad is based on the participants' personal experiences, accumulated stereotypes and on the country's actions and communications. There is no clear relatedness of what actions of what entity are being assessed. This echoes the findings of the study conducted by Sommerfledt and Buhmann (2019) where they discussed the concept of attribution and its relation to the evaluation of impact. Cultural diplomacy practitioners need to be cautious of what they call "evaluation of perceptions" and the "measurement of reputation" in that they need to be specific about what kind of actions they are evaluating. Thus, many questions need to be raised and thought of:

- Are we evaluating the impact of Morocco's economic diplomacy, public diplomacy or cultural diplomacy?" 
- Whose actions are we evaluating?

- $\quad$ Are they the actions of Ministerial departments? Moroccan Cultural Centers? Morocco's embassies abroad? NGO's actions? Or private initiatives?

All of these elements need to be taken into consideration to be able to provide accurate and valid information on the impact of Moroccan cultural diplomacy.

Equally important, claiming that the study carried out by the Royal Institute of Strategic Studies is related to the impact of Moroccan Cultural Diplomacy raises the question whether the impact of cultural diplomacy can be evaluated on a yearly basis. As explained in the review, the outcomes of cultural diplomacy cannot be seen until after a long period of time. The literature speaks about five years for intermediate outcomes and more for long-term outcomes. That is to say, claiming that within a period of time of twelve months, much of the foreign audiences' attitudes and behaviors would change is again a big claim. It is practically and scientifically impossible unless the impact evaluated is not that of cultural diplomacy. Therefore, Moroccan cultural diplomacy practitioners need to take into consideration that "concrete change needs time". As discussed in the review, according to Gonzalez (2015), within the PD spectrum, behavioral shifts and call to action require decades to be achieved and the same can be said about cultural diplomacy. Also, Cull's metaphor (2005) can be evoked at this point to explain how difficult cultural diplomacy impact evaluation can be.

\subsection{A unit specialized in the evaluation of Moroccan cultural diplomacy: convergence rather than divergence?}

The Directorate of Cooperation and Cultural Action acts as a mediator of communication between multiple cultural diplomacy stakeholders. It is also in charge of formulating and implementing cultural events and programs abroad. Therefore, officials within the Directorate are immersed with the different tasks they are assigned to do on a daily basis especially that the Directorate suffers from a deficit in terms of the availability of staff operating within the Department. Little room can be thus devoted to developing real cultural diplomacy impact evaluation indicators. This echoes the findings discussed in the literature review regarding the impossibility of relying on public diplomacy officials (in this case cultural diplomacy officials) to perform such tasks. In addition to this, each cultural diplomacy stakeholder relies on its own performance indicators to measure the impact of its own actions. This causes a lack of clarity and accentuates the ambiguity of "who is doing what". In the Moroccan context, no entity has as a main mission the evaluation of the impact of Moroccan cultural diplomacy. Therefore, in addition to creating a unifying organism in charge of carrying out unified cultural actions, the creation of a unit, bureau or department in charge of evaluating the impact of all cultural diplomacy actions has become a necessity to solve problems of dispersion and attribution.

Furthermore, the lack of human resources specialized in impact evaluation constitutes a factor that prevents the implementation of systematic evaluation indicators. The multidisciplinary training has limitations. While it can be agreed that multidisciplinary training allows diplomats to acquire knowledge on many issues, and many officials within the Ministry praise its utility, cultural diplomacy, given its complex nature, requires the training of profiles who truly understand the mechanisms of soft power practices. Along with profiles trained in other fields, each in their domains of specialization can form a well-equipped team or board dedicated to developing an effective cultural diplomacy strategy. Thus, two issues need consideration, the creation of a unit exclusively in charge of carrying out impact evaluation processes and the consideration of agents trained in the field.

\subsection{Impact evaluation or output evaluation?}

The evaluation indicators used by the Moroccan Ministry of Foreign Affairs are limited to output generation. These tools fail to measure the intangible objectives that cultural diplomacy aims to pursue. Evoking what was discussed in the review concerning the goals of evaluation, the indicators used by the Moroccan Ministry of Foreign Affairs do not give account of how trust has been established with foreign audiences, how cultural diplomacy actors are perceived or how the preferences and choices made by the target groups have been affected. The questions to ask in this context are as follows: "Does public opinion matter for Moroccan cultural diplomacy practitioners?" If the objectives behind the implementation of cultural diplomatic programs are the establishment of cultural influence and a better image of Morocco, how do Moroccan CD practitioners know what "others" think about "them"? "How is Morocco perceived abroad?", "how many countries support Morocco's sovereignty over the Moroccan Sahara as a result of Moroccan cultural diplomacy? "Can we answer these questions relying on narrative reports posts abroad send after every flagship event? Through the number of cultural agreements concluded with other countries? Through the number of cultural events and programs carried out abroad?" Or through the amount of money spent on those programs?" As Gonzalez (2015) points out, these indicators are not irrelevant because they allow performance measuring and tracking. It is also true that they form an essential part of any serious evaluation strategy but they stop short of the ultimate goal; to know if the inputs and resources invested left a lasting effect on our intended audience. 


\subsection{Towards a logic-model-based strategy:}

While the adaptive strategy seems to be effective in crisis management, less time and resource consuming, it does not produce long-term results. The adaptive strategy does not allow the development of a long-term vision as it is focused on instant problemsolving. In addition, it stops short of the deployment of appropriate evaluation indicators. Therefore, the logic model can be of great use in strategizing and program planning. In Morocco, the logic model will allow:

- The development of a longer-term strategy.

- The detection of any unforeseen issues, anticipation and intervention without having to reconsider modifying the whole strategy.

- The development of suitable indicators dedicated to assessing performance and impact.

As suggested by Mccwlay (2001), strategizing using the logic model should consider the following elements: the situation to be changed, the impact to be achieved, the intermediate outcomes and the output to be generated, the activities that will contribute to the achievements of all these elements all the way down to the input or resources needed for the completion of programs. The figure below suggests how the logic model can be applied to the Moroccan context:

Figure 3: The logic-model-based strategy suggested in this paper

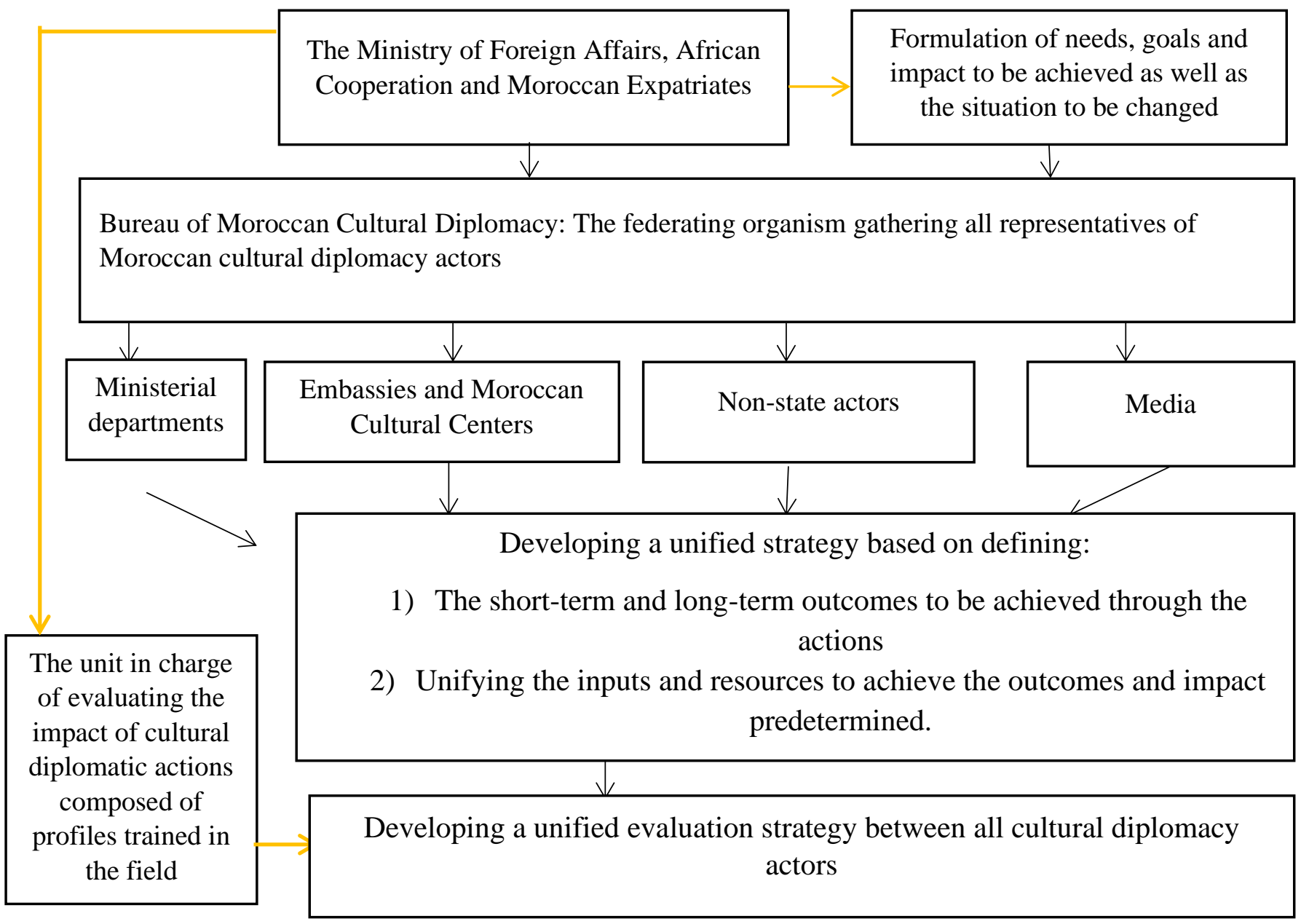

As presented in the figure above, Moroccan cultural diplomacy actors should get around one table to unify their efforts. Coordination among posts will solve issues of attribution and dispersion of actions. Strategizing using the logic model requires the development of a unified cultural diplomacy strategy between all the actors involved in it. As suggested in previous sections, the creation of a federating organism could be one step forward to achieving uniformity. Once a unified strategy is set between all actors, developing an agreed-upon evaluation strategy will be an easy task. These steps will allow cultural diplomacy practitioners to have clearer visions on what their goals are and how these goals can be achieved using the financial resources 
available. This is necessary if Moroccan cultural diplomacy practitioners are willing to appropriately make use of the rich Moroccan cultural capital.

\section{Conclusion}

This paper has examined how the Moroccan Ministry of Foreign Affairs evaluates the impact of cultural diplomacy abroad. It states that measurement is carried out based on reports elaborated by posts and through the study of Morocco's reputation abroad performed by the Royal Institute of Strategic Studies. The paper also discusses the challenges that Moroccan cultural diplomacy faces and how these challenges hinder the elaboration of appropriate evaluation tools. However, the study concludes that the strategy deployed to conduct cultural diplomacy constitutes a major factor that makes impact evaluation a difficult task. In Morocco, the adaptive strategy and the short-term planning were revealed to be instantaneously effective but unable to have longer-term effects. Therefore, long-term planning using the logic model as suggested above enables a clear identification of the goals to be achieved and gives a clearer idea of the suitable tools to evaluate that impact. With this comes the inevitable creation of an entity that gathers all Moroccan cultural diplomacy actors namely state actors, non-state actors and the media to achieve the unification of their actions instead of the dispersion they currently suffer from. It is also very important to consider establishing a unit or department dedicated to measuring the impact of cultural diplomacy composed of profiles trained in this area. These insights can solve problems of attribution and the lack of inter-institutional coordination between Moroccan cultural diplomacy actors. Above all, going back to academia is an important step forward to learn more about the practices of soft power because the implementation of any practice should be based on a strong understanding of its mechanisms. The present study has limitations. It has highlighted the tools and methods used in the evaluation of Moroccan cultural diplomacy; however, it does not suggest specific impact indicators. This can be the subject of another study bringing together different profiles in the cultural diplomacy area, management controllers and statisticians.Future research in the field of Moroccan cultural diplomacy needs to consider the data presented in this paper in order to elaborate effective evaluation tools for the measurement of the impact of Moroccan cultural diplomacy.

Funding: This research received no external funding.

Acknowledgments: We thank the staff of the Ministry of Foreign Affairs, African Cooperation and Moroccan Expatriates for their support and availability.

Conflicts of Interest: The author declares no conflict of interest.

\section{References:}

[1] Bank, R. (2011). A Resource guide to public diplomacy evaluation. CPD perspectives on public diplomacy. FIGUEROA Press

[2] Buhmann, A. Sommerfledt, E.J. (2019). The Status quo of evaluation in public diplomacy: insights from the U.S state department. Journal of Communication and Management. http: //doi.org/10.1108/JCOM-12-2018-0137

[3] Buhmann, A. Sommerfledt, E.J. (2020). Pathways for the future of evaluation in public diplomacy. FIGUEROA Press

[4] Brown, K. (2017). Challenges in measuring public diplomacy. The Soft Power 30. https://softpower30.com/challenges-in-measuring-publicdiplomacy/

[5] Creswell, J. W. (2014). Research design: Qualitative, Quantitative, and Mixed Methods Approaches. SAGE publications.

[6] Cummings, M.C. (2009). Cultural diplomacy in the United States Government: A survey. Center for Arts and Culture

[7] Gonzalez, C. (2015). The Evaluation revolution of public diplomacy. Council of American Ambassadors. https://www.americanambassadors.org/publications/ambassadors-review/fall-2015/the-evaluation-revolution-in-public-diplomacy

[8] Griffith, R.R. Zhang, G. Using the context, input, process, and product evaluation model (CIPP) as a comprehensive framework to guide the planning, implementation and assessment of service learning programs. (2011). Journal of Higher Education Outreach and Engagement, 15(4).

[9] L'Institut Royal des Etudes Stratégiques. The RepTrak Company. (2020). La Réputation du Maroc dans le Monde.

[10] Le Discours du Roi: Message du Souverain à la 1ère conférence des ambassadeurs de SM le Roi. (2013). https://www.maroc.ma/fr/discoursroyaux/le-souverain-adresse-un-message-la-1ere-conference-des-ambassadeurs-de-sm-le-roi

[11] Mccawley, P. (2001). The logic model for program planning and evaluation. https://www.researchgate.net/publication/237568681_The_Logic_Model_for_Program_Planning_and_Evaluation

[12] Nicholas, J.C. (2007). Public diplomacy: lessons from the past. FIGUEROA Press

[13] Roche, C. (1999). Impact assessment for development agencies. Oxford: Oxfam/NOVIB.

[14] Singh, J.P., MacDonald, S., Son, B. (2018). Soft power today: measuring the influences and effects. British Council. University of Edinburgh.

[15] Stufflebeam, D. L. Shinkfield, A.J. (2007). Evaluation theory, models, and applications. Jossey-Bass.

[16] Tuomoija, E. Comment on cultural diplomacy. Academy for Cultural Diplomacy. http://www.culturaldiplomacy.org/academy/index.php?oncultural-diplomacy-a-brief-statement-on-the-cultural-diplomacy-in-the-contemporary-world-1

[17] Vinter, L. Knox, D. (2008). Measuring the impact of public diplomacy: can it be done? In J. Welsh, D. Fearn, A. Mackay, F. Sinclair, T. Smart (Eds). Engagement: Public diplomacy in a globalized world. (160-170). Foreign and Common Wealth Office. 